\title{
Kinesiophobia is not required to predict chronic low back pain in workers: a decision curve analysis
}

\author{
A. M. Panken ${ }^{1,2^{*}} \mathbb{D}$, J. B. Staal ${ }^{3}$ and M. W. Heymans ${ }^{1}$
}

\begin{abstract}
Background: Currently used performance measures for discrimination were not informative to determine the clinical benefit of predictor variables. The purpose was to evaluate if a former relevant predictor, kinesiophobia, remained clinically relevant to predict chronic occupational low back pain (LBP) in the light of a novel discriminative performance measure, Decision Curve Analysis (DCA), using the Net Benefit (NB).

Methods: Prospective cohort data $(n=170)$ of two merged randomized trials with workers with LBP on sickleave, treated with Usual Care (UC) were used for the analyses. An existing prediction model for chronic LBP with the variables 'a clinically relevant change in pain intensity and disability status in the first 3 months', 'baseline measured pain intensity' and 'kinesiophobia' was compared with the same model without the variable 'kinesiophobia' using the NB and DCA.

Results: Both prediction models showed an equal performance according to the DCA and NB. Between 10 and 95\% probability thresholds of chronic LBP risk, both models were of clinically benefit. There were virtually no differences between both models in the improved classification of true positive (TP) patients.

Conclusions: This study showed that the variable kinesiophobia, which was originally included in a prediction model for chronic LBP, was not informative to predict chronic LBP by using DCA. DCA and NB have to be used more often to develop clinically beneficial prediction models in workers because they are more sensitive to evaluate the discriminate ability of prediction models.
\end{abstract}

Keywords: Low Back pain, Prognosis, Prediction model, Kinesiophobia, Decision curve analysis

\section{Introduction}

The development of prediction models has grown in popularity in Low Back Pain (LBP) research [1-3]. Prediction models can help clinicians as physical therapists in daily practice in making a prognosis and provide an estimate of the probability of persisting symptoms for individual patients [4]. This probability estimate may be an

\footnotetext{
* Correspondence: a.panken@amsterdamumc.nl

'Department of Epidemiology and Biostatistics, Amsterdam Public health research Institute, Amsterdam UMC, Vrije Universiteit Amsterdam, Amsterdam, The Netherlands

${ }^{2}$ Physical Therapy Practice Panken, Roermond, The Netherlands

Full list of author information is available at the end of the article
}

indication for the clinician to adjust the treatment goals to the patient needs.

A recent literature review showed that most prediction models (developed for physical therapists) do not use performance measures that evaluate the clinical usefulness of the models well [5]. Performance measures as Receiver Operating Characteristic Curve (ROC curve), the Area Under this Curve (AUC), sensitivity and specificity, in combination with a low and high risk cutoff point can be used to determine the clinical feasibility of a developed prediction model. However, these measures have shown to be less sensitive in evaluating the added

(c) The Author(s). 2020 Open Access This article is licensed under a Creative Commons Attribution 4.0 International License, which permits use, sharing, adaptation, distribution and reproduction in any medium or format, as long as you give appropriate credit to the original author(s) and the source, provide a link to the Creative Commons licence, and indicate if changes were made. The images or other third party material in this article are included in the article's Creative Commons licence, unless indicated otherwise in a credit line to the material. If material is not included in the article's Creative Commons licence and your intended use is not permitted by statutory regulation or exceeds the permitted use, you will need to obtain permission directly from the copyright holder. To view a copy of this licence, visit http://creativecommons.org/licenses/by/4.0/. The Creative Commons Public Domain Dedication waiver (http://creativecommons.org/publicdomain/zero/1.0/) applies to the data made available in this article, unless otherwise stated in a credit line to the data. 
discriminative performance of a predictor and do not provide direct feedback on the number of chronic LBP patients that are correctly classified and are therefore less clinically useful [6-8]. A novel performance measure to evaluate the discriminative ability of a prediction model is Decision Curve Analysis (DCA) and the Net Benefit (NB) [9]. This method is able to identify the number of patients that are better classified and incorporate clinical consequences of using a model, which is useful for clinicians [7]. Furthermore, this novel method is recommended by recent guidelines to develop prediction models (Transparent Reporting of a multivariable prediction model for Individual Prognosis Or Diagnosis (TRIPOD) statement) [10]. Remarkably is that this method has not been used frequently by LBP researchers yet. To our opinion, until now only two studies predicting LBP using DCA, were published [11, 12]. Heymans et al. published a model to predict chronic LBP in workers that included the variables of a 'clinically relevant decrease in pain intensity and in disability status in the first 3 months', 'pain intensity at baseline' and 'kinesiophobia' [13]. The importance of kinesiophobia as a prognostic factor for chronic LBP was suspect. The fearavoidance model was originally developed to explain the transition from acute to chronic pain [14]. However, there was conflicting evidence in the literature about the clinical usefulness of kinesiophobia as a predictor for chronic LBP. Gheldof et al. stated that, fear of movement measured with the Tampa scale only was a risk factor in case of failure to recovery from short-term LBP [15]. The impact of kinesiophobia on the transition from subacute to chronic LBP was also reported in the studies of Heneweer et al. [16] and Swinkels-Meewisse et al. [17]. Also, Dawson et al. stated that kinesiophobia increased the likelihood of sick leave due to LBP [18]. Furthermore Lakke et al. showed in a synthesis of evidence from systematic reviews (SRs) that kinesiophobia was often included in studies as a possible predictive variable, although this was not always justified [19]. So, the objective of the current study is to evaluate if kinesiophobia is a clinically relevant predictor of chronic LBP in the light of the novel discriminative performance measure, Decision Curve Analysis (DCA), using the Net Benefit (NB) because this measure is more suitable to test the predictive performance of separate predictor variables.

\section{Methods}

\section{Study design}

A prospective cohort study $(\mathrm{n}=170)$ was used by merging data from workers on sick-leave with LBP that received usual care (UC), in two randomised controlled trials (RCTs) $[20,21]$. This study was reported in accordance with the strengthening the reporting of observational studies in epidemiology (STROBE) statement [22]. These RCTs were conducted at the same department, within the same time frame, were similar in design, used the same baseline and follow-up variables and the same in/exclusion criteria: patients with non-specific LBP, on sickleave for 4-8 weeks, visited their occupational physician. For detailed information about the data merging process see Heymans et al. [13]. Both RCTs were approved by the medical ethical committee

\section{Outcome measure}

Pain intensity was assessed on a Numerical Rating Scale (NRS) at baseline, 3 and 6 months [23]. The outcome measure chronic LBP $(0=$ no, $1=$ yes $)$ was defined as having a pain intensity score of $\geq 4$ at baseline and $\geq 3$ at three and 6 months of follow-up [13, 24].

\section{Prediction models used in this study}

The models were derived from the study published in 2010 [13]. In the current study, the value of the variable 'kinesiophobia' was studied comparing the following models.

Model 1 consisted of the variables 'pain intensity at baseline,' a 'clinically relevant change in pain intensity [21] and in disability status [25] in the first 3 months'. A clinically relevant change in pain and disability was noted by a change of 3 and 4 points on the NRS and Roland Disability Questionnaire (RDQ) respectively within the first 3 months after the LBP episode [26, 27]. Model 2 was model 1, plus an extra variable under study: 'kinesiophobia' [28].

\section{Statistical analysis}

A logistic regression model was used to study the relationship between the outcome measure and the aforementioned predictors. In the original paper of Heymans et al. [13], the variables 'Pain intensity at baseline' missed $3 \%$ of the data, 'kinesiophobia' $6,2 \%$, 'change in pain intensity in the first 3 months' $19,7 \%$ and 'change in functional status in the first 3 months' $23,7 \%$ missing data. These missing values were replaced by applying multiple imputation (MI) by using the Multiple Imputation by Chained Equations package [29]. For the current study the first imputed dataset (from 10) was used from the original study to evaluate the DCA analysis of the prediction models that compared the inclusion of the kinesiophobia variable. This procedure was followed for practical reasons because if we had used all multiple imputed datasets from the original study, we had to somehow pool all DCA and Net Benefit results when they were applied in each imputed dataset and these pooling methods are not available. Moreover, our study goal was to compare DCA and Net Benefit of two prediction 
models and we think that we were still able to fulfill that goal accurately by using one of the imputed datasets because the regression coefficient estimates in this dataset were strongly comparable to the pooled estimates from the original study. The AUC values (95\% Confidence Intervals) of each model were also presented. All statistics were done with R software using Harrell's rms package.

\section{Decision curve analysis}

Decision curve analysis (DCA) is a method to evaluate the net benefit $(\mathrm{NB})$ of a prediction model across clinicians and patient preferences for accepting the risk of under- or overtreatment $[9,30]$. The decision to treat depends on the benefits (effectiveness) and harms (complications, costs) of the treatment. For this, in DCA the 'probability threshold' $\left(\mathrm{p}_{\mathrm{t}}\right)$ is important: a level of certainty of the outcome above which the patient would choose to be treated. This threshold includes the relative value of the patient for receiving treatment when thinking he/she develops chronic LBP in relation to the value of avoiding treatment thinking he/she will recover from LBP. If the treatment is effective with minimal costs and risk of complications this threshold will be low. On the other hand, if the treatment is associated with high intensity, minimal effect and high costs, the threshold will be high. The net benefit (NB) is calculated by the difference between the expected benefit and harm associated with the treatment. The expected benefit incorporates the number of patients who will correctly develop chronic LBP according to the prediction model and will be treated: the true positive patients (TP). The expected harm incorporates the number of patients who will recover from LBP but would be treated (the false positives $=$ FP) multiplied by a weighting factor based on the patient's threshold probability. In formula: $\mathrm{NB}=(\mathrm{TP}-w$ $\mathrm{FP}) / \mathrm{N}$, where $\mathrm{N}$ is the total number of patients and the $w$ in the NB formula is described by $\mathrm{p}_{\mathrm{t}} /\left(1-p_{\mathrm{t}}\right)$. For example, a physiotherapist uses a prediction model to determine the probability of developing chronic LBP and wonders if a patient with a probability of $30 \%$ according to the model has to be treated by an exercise program. In formula: $\mathrm{w}=0.3 /(1-0.3)=0.43$, which means that the number of FP patients in the NB formula gets less weight and that unnecessary treatment is less important than missing treatment (because $\mathrm{w}$ is multiplied by FP). When the patient worries about the LBP and/or the treatment is effective, cheap and not intensive, a physical therapist could decide to treat the patient at this low risk of chronic LBP [21]. A physical therapist that uses a higher $\mathrm{p}_{\mathrm{t}}$ of $70 \%(\mathrm{w}=0.7 / 0.3=2.33)$, assumes FP decisions more harmful. This may play a role in case of intensive and costly exercise programs [21]. Because patients and clinicians may value harms and benefits differently, the NB can be calculated for different value of $\mathrm{p}_{\mathrm{t}}$ 's and compared to the $\mathrm{NB}$ of treating all patients (assuming everybody develops chronic LBP and needs treatment) or treating no patients (assuming nobody develops chronic LBP). This can be graphically depicted by making a decision curve. A higher NB value means that the model will be more clinically useful as indicated by the higher number of TP patients that are identified. Further, the NB of prediction model 1 can be compared to the NB of prediction model 2 at each level of $\mathrm{p}_{\mathrm{t}}$ and it can be evaluated if the variable 'kinesiophobia' is needed to improve the predictive performance of the prediction model. This will be further clarified and explored in the results section.

\section{Results}

Table 1 showed the patients characteristics of all occupational LBP patients $(n=170)$ of which 91 patients developed chronic LBP (53.5\%).

Table 2 showed the strength of the relationships of the variables in the two prediction models.

Model 2 (with the added variable 'kinesiophobia') did not perform better compared to Model 1 given the AUC of 0.862 compared to the AUC of model 1 of 0.858 . Further, the strength of all variables in the models remained the same and the variable 'kinesiophobia' in Model 2 showed an insignificant OR of 1.05 with $95 \%$ CI of $0.99-1.11$.

\section{Decision curve analysis \\ Comparing both prediction models at one threshold probability}

First, our comparison started with an example of the calculation of the NB for prediction model 1, the model without the variable 'kinesiophobia' at a $\mathrm{p}_{\mathrm{t}}$ of $30 \%$ by using Table 3. At a $\mathrm{p}_{\mathrm{t}}$ of $30 \%$ the number of TP patients according to the prediction model was 86 and the number of FPs was 38. With a total number of patients of 170 the $\mathrm{NB}=86 / 170-(38 / 170 \times(0.3 / 0.7))=0.410$. This NB meant that a net 41 TP patients per 100 patients was identified, compared to assuming that all patients did not develop chronic LBP, at the same number of FP

Table 1 Patient characteristics at baseline $(n=170)$ of the LBP patients

\begin{tabular}{lll}
\hline & Value & Observed range \\
\hline Age (mean years \pm SD) & $39.4(9.2)$ & $18-59$ \\
Gender (number male (\%)) & $146(85.8)$ & - \\
Pain intensity (NRS) (mean \pm SD) & $6.45(1.9)$ & $0-10$ \\
Kinesiophobia (mean \pm SD) & $39.6(6.8)$ & $23-62$ \\
Change in pain intensity (\%) & $100(58.8)$ & - \\
Change in functional disability (\%) & $110(64.7)$ & - \\
Chronic Low Back Pain (\%) & $91(53.5)$ & -
\end{tabular}

SD standard deviation, NRS numerical rating scale 
Table 2 Odds ratios (OR) of the 2 prediction models compared

\begin{tabular}{lll}
\hline Prediction Models & OR $(95 \% \mathrm{Cl})$ & AUC $(95 \% \mathrm{Cl})$ \\
\hline Model 1 & & $0.858(0.780 ; 0.917)$ \\
Change in pain intensity & $4.09(0.83 ; 20.11)$ & \\
Change in functional disability & $8.57(1.59 ; 46.25)$ & \\
Pain Intensity at baseline & $2.10(1.59 ; 2.77)$ & \\
Model 2 & & $0.862(0.805 ; 0.920)$ \\
Change in pain intensity & $3.64(0.76 ; 17.47)$ & \\
Change in functional disability & $10.43(1.92 ; 56.72)$ & \\
Pain Intensity at baseline & $2.01(1.52 ; 2.66)$ & \\
Kinesiophobia & $1.05(0.99 ; 1.11)$ & \\
\hline
\end{tabular}

patients. The calculation of the $\mathrm{NB}$ for prediction model 2, that also included the variable 'kinesiophobia', was $84 / 170-(33 / 170 \times(0.3 / 0.7))=0.411$. The interpretation of this NB was that a net 41 TP patients per 100 patients was identified, compared to assuming all patients were negative, at the same number of FP patients. At this level of $\mathrm{p}_{t}$ the NB of both models were similar and the prediction was not improved by including the variable 'kinesiophobia'.

When it was assumed that all patients were positive and developed chronic LBP, the NB was calculated as $\mathrm{NB}=91 / 170-(79 / 170 *(0.3 / 0.7))=0.336$. This value was lower as the NB of prediction model 1 and 2 above, which meant that both the prediction models were more of clinical benefit at a $\mathrm{p}_{\mathrm{t}}$ of $30 \%$ than just assuming everybody had LBP and treat them accordingly. The difference in NB between both prediction models and assuming that all patients were positive was $\left(\mathrm{NB}_{\text {model }}-\right.$ $\left.\mathrm{NB}_{\text {treat all }}\right) * 100=(0.411-0.336) * 100=7.5$. This meant that a net $8 \mathrm{TP}$ patients was identified by using the prediction models compared to treating all patients,

Table 3 Relationship between chronic LBP and results of a prediction models with a predicted probability of chronic LBP of $30 \%$

\begin{tabular}{llllll}
\hline Model 1 & Chronic LBP & No Chronic LBP & Total & NB & N \\
$\begin{array}{l}\text { Probability of } \\
\text { chronic LBP } \geq 30 \%\end{array}$ & 86 & 38 & 124 & 0.410 & 41 \\
$\begin{array}{l}\text { Probability of } \\
\text { chronic LBP }<30 \%\end{array}$ & 5 & 41 & 46 & & \\
& 91 & 79 & 170 & & \\
Model 2 & Chronic LBP & No Chronic LBP & Total & NB & $n$ \\
$\begin{array}{l}\text { Probability of } \\
\text { chronic LBP } \geq 30 \%\end{array}$ & 84 & 33 & 117 & 0.411 & 41 \\
$\begin{array}{l}\text { Probability of } \\
\text { chronic LBP }<30 \%\end{array}$ & 7 & 46 & 53 & & \\
& 91 & 79 & 170 & &
\end{tabular}

NB Net Benefit at probability threshold $\left(\mathrm{p}_{\mathrm{t}}\right)$ of $30 \%$

$N$ amount of true positive identified patients per 100 patients, compared to assuming that all patients did not develop chronic LBP, at the same number of false positive patients without an increase in de number of FP patients. Comparing prediction models 1 and 2, where model 2 contained the extra predictor 'kinesiophobia', at a $\mathrm{p}_{\mathrm{t}}$ of $30 \%$, there was no difference in NB between these models.

\section{Comparing both prediction models at various threshold probabilities - the decision curve}

On the decision curve the NB of the prediction models (y-axis) according to the various threshold probabilities $\mathrm{p}_{\mathrm{t}}$ (x-axis) was plotted. The NBs of the prediction models 1 and 2 were shown in Fig. 1.

It could be seen in Fig. 1 that there were virtually no differences between prediction models 1 and 2 in NBs, i.e. adding 'kinesiophobia' did not increase the NB over the whole range of $\mathrm{p}_{\mathrm{t}}$ 's. Table 4 showed the differences in NBs and the improvement in the detection of TP patients of prediction model 2 compared to model 1 at different $\mathrm{p}_{\mathrm{t}}$ 's. Both models had a higher NB compared to treating everybody over the range of $\mathrm{p}_{\mathrm{t}}$ 's of $10 \%$ to just over $50 \%$. This improvement resulted in the identification of more TP patients for both models compared to treating everybody. Further, prediction model 1 and 2 had slightly the same NBs. Over the whole range of $\mathrm{p}_{\mathrm{t}}$ 's they alternated in the identification of marginally more TP patients. This meant that the variable 'kinesiophobia' was not necessary to improve the prediction of chronic LBP.

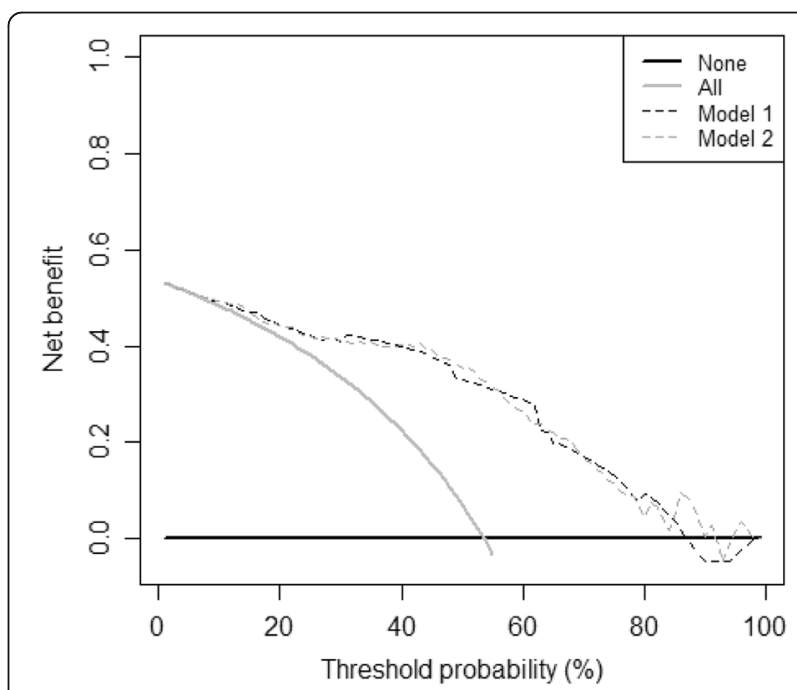

Fig. 1 Decision curves of the prediction Models 1 and 2 to predict chronic LBP. Y-axis is Net Benefit and $x$-axis is threshold probability $\mathrm{p}_{\mathrm{t}}$. Dotted black line belongs to the Net Benefit of prediction Model 1, dotted grey line to Model 2. The black line is the Net Benefit when all patients are assumed negative and the grey line is the Net Benefit when everybody is assumed positive and would be treated. * The Net Benefit of the model around $90 \%$ is sometimes negative due to random noise [9] 
Table 4 Net Benefits of prediction Models 1 and 2 compared to the NB of treating nobody or everybody and the consequences for the number of TPs at probability thresholds ranging from 5 to $60 \%$

\begin{tabular}{lllllll}
\hline $\mathrm{Pt}^{\mathrm{a}}$ & NB Model $^{b}$ & NB Model $2^{b}$ & NB treat all & $\begin{array}{l}\text { TP M1 } \\
\text { vs all }\end{array}$ & $\begin{array}{l}\text { TP M2 } \\
\text { Vs all }\end{array}$ & $\begin{array}{l}\text { TP M2 } \\
\text { vs M1 }\end{array}$ \\
\hline 0.05 & 0.513 & 0.513 & 0.511 & 0 & 0 & 0 \\
0.1 & 0.493 & 0.493 & 0.484 & 1 & 1 & 0 \\
0.2 & 0.444 & 0.441 & 0.419 & 2 & 2 & 0 \\
0.3 & 0.410 & 0.411 & 0.336 & 7 & 7 & 0 \\
0.4 & 0.398 & 0.402 & 0.225 & 17 & 18 & 0 \\
0.5 & 0.329 & 0.353 & 0.071 & 26 & 28 & 2 \\
$0.6^{\mathrm{e}}$ & 0.288 & 0.265 & -0.162 & 45 & 43 & -2 \\
\hline
\end{tabular}

${ }^{a} P_{t}$ is threshold probability

${ }^{\mathrm{b}}$ NB is Net Benefit of the Model compared to assuming everybody does not develop chronic LBP

c TP is the increase in number of true positive patients when the Model is compared to assuming everyone has chronic LBP

${ }^{d}$ TP is the increase in number of true positive patients when Model 2 is compared to Model 1

e Only comparison until $60 \%$ was feasible because the NB for treat all was negative at higher percentages

\section{Discussion}

\section{Main findings}

In 2010 it was shown by Heymans et al. [13] that a prediction model including 'pain intensity at baseline',

'kinesiophobia' and a 'clinically relevant decrease in pain intensity and in disability status in the first 3 months' predicted chronic LBP well. The finding that changes in the initial LBP and functional status period were relevant to predict chronic LBP later in time was demonstrated in more studies [31-34]. In the current study it was shown that the variable 'kinesiophobia' was not required to predict chronic occupational LBP in workers by using the novel performance measures DCA and NB.

\section{Decision curve analysis}

Often it was not totally clear when a prediction model was of benefit for clinicians and/or patients. It made therefore sense to evaluate the clinical value of the model at different levels of threshold probabilities by using the NB. For example, when patients worried about their LBP, the physical therapist might want to know if the model was still of benefit at low risk probabilities. The patient might then be successfully referred to a low intensive and cheap intervention program [21]. To know at which probability threshold the prediction model was clinically useful, we had to know what kind of risk probabilities physical therapists used in practice and what kind of harm and benefits were acceptable for physical therapists and patients. That was challenging for LBP because physical therapists might think differently about LBP and the consequences of treatment for their patients.

\section{Strengths and limitations}

Performance measures as sensitivity and specificity could be used to determine the discriminative ability of a prediction model. However, these measures are less suitable to test the predictive performance of separate predictor variables [6]. Sensitivity or specificity may decrease even when the ROC curve of one model uniformly dominates the ROC curve of the other model. The NRI and decision-analytic measures will agree in sign in reasonable scenarios [8].

Therefore, the sensitivity, specificity and ROC curve were not considered in this study. A limitation could be that our model was only internally validated, however internal validation was sufficient to allow the use of DCA [35]. Our definition of chronic LBP was not applicable to all types of chronic LBP patients in practice. For example, the prognosis of patients with pain free episodes (not identified by our definition) might be determined by other variables for chronic LBP. Furthermore, our definition was determined on the level of pain intensity. It had been argued that chronic LBP may not only be based on pain intensity but also on limitations in function [36]. However, recent studies showed that LBP pathways were linked to functional disability in such a way that if one knew the level of pain intensity, also the level of functional limitations could be determined and vice versa [34]. Another limitation is that data were used from RCTs rather than observational studies. RCTs apply strict inclusion and exclusion criteria that can for example result in a more homogeneous patient population that may affect the performances of the prediction model [4]. Consequently, this may hamper the generalization of results to a group of patients that is seen in daily practice.

\section{Conclusion}

In our study 'kinesiophobia' (measured by the TS) seemed not required to improve the prediction of chronic occupational LBP and that it was not needed to adapt the treatment strategy. The performance measures NRI and DCA were not used in LBP research and practice yet. Why these measures were not used is unclear. Perhaps because the most published articles concerning the NRI and NB methods were published in methodological or statistical oriented journals. Although, the use of probability thresholds was mentioned before for physical therapists within the context of clinical decision making [37, 38]. The DCA gave the best insight in the clinical usefulness of prediction models for physical therapists. They could translate clinical usefulness and benefits in terms of number of TP patients that were identified, which is attractive for healthcare professionals and their patients especially in the light of making good treatment decisions. 


\section{Abbreviations}

AUC: Area under this curve; DCA: Decision curve analysis; FP: False positive; LBP: Low back pain; NB: Net benefit; NRS: Numerical rating scale; $\mathrm{p}_{\mathrm{t}}$ : Probability threshold; RCT: Randomized clinical trial; ROC: Receiver operating characteristic; STROBE: Strengthening the reporting of observational studies in epidemiology; TP: True positive; TRIPOD: Transparent Reporting of a multivariable prediction model for individual prognosis or diagnosis; UC: Usual care

\section{Acknowledgements}

$\mathrm{Na}$

\section{Authors' contributions}

$\mathrm{MH}$ developed the study concept and design. AP and $\mathrm{MH}$ performed the data analysis, interpretation of results and wrote and drafted the manuscript and JS critically reviewed the manuscript. The authors read and approved the final manuscript.

\section{Funding}

This study was granted by the WCF (Scientific College Physical Therapy). The funding body had no role in study design, the collection, analysis and interpretation of data; in the writing of the manuscript and in the decision to submit the manuscript for publication.

\section{Availability of data and materials}

The datasets used and/or analysed during the current study are available from the first author on reasonable request.

\section{Ethics approval and consent to participate}

NA

\section{Consent for publication}

NA

\section{Competing interests}

The authors declare that they have no competing interests.

\section{Author details}

'Department of Epidemiology and Biostatistics, Amsterdam Public health research Institute, Amsterdam UMC, Vrije Universiteit Amsterdam, Amsterdam, The Netherlands. ${ }^{2}$ Physical Therapy Practice Panken, Roermond, The Netherlands. ${ }^{3}$ Han University of applied sciences, Nijmegen, The Netherlands.

\section{Received: 13 February 2019 Accepted: 3 March 2020}

Published online: 12 March 2020

\section{References}

1. Thomas E, Silman AJ, Croft PR, et al. Predicting who develops chronic low back pain in primary care: a prospective study. BMJ. 1999:318(7199):1662-7.

2. Dionne CE, Koepsell TD, Von Korff M, et al. Predicting long-term functional limitations among back pain patients in primary care settings. J Clin Epidemiol. 1997;50(1):31-43.

3. Heymans MW, Anema JR, van Buuren S, et al. Return to work in a cohort of low back pain patients: development and validation of a clinical prediction rule. J Occup Rehabil. 2009;19(2):155-6.

4. Steyerberg EW. Clinical Prediction Models. A Practical Approach to Development, Validation, and Updating (2nd edition). Switzerland: Springer Nature; 2019.

5. Oort L, van, Berg T, van den, Koes B et al. Preliminary state of development of prediction models for primary care physical therapy: a systematic review. J Clin Epidemiol 2012;65:1257-1266.

6. Pencina MJ, D'Agostino RB Sr, D'Agostino RB Jr, et al. Evaluating the added predictive ability of a new marker: from area under the ROC curve to reclassification and beyond. Stat Med. 2008;27:157-72.

7. Vickers AJ, van Calster B, Steyerberg E. Net benefit approaches to the evaluation of prediction models, molecul markers, and diagnostic tests. BMJ. 2016;352:16.

8. van Calster B, Vickers AJ, Pencina MJ, et al. Evaluation of markers and risk prediction models: overview of relationships between NRI and decisionanalytic measures. Med Decis Mak. 2013 May;33(4):490-501.
9. Vickers AJ, Elkin EB. Decision curve analysis: a novel method for evaluating prediction models. Med Decis Mak. 2006;26(6):565-74.

10. Moons KG, Altman DG, Reitsma JB, et al. Transparent reporting of a multivariable prediction model for individual prognosis or diagnosis (TRIPOD): the TRIPOD statement. Ann Intern Med. 2015;162(1):W1-73.

11. Karran EL, Traeger AC, McAuley JH, et al. The value of prognostic screening for patients with low back pain in secondary care. J Pain. 2017;18(6):673-86.

12. Traeger AC, Henschke $N$, Hübscher $M$, et al. Estimating the risk of chronic pain: development and validation of a prognostic model (PICKUP) for patients with acute low back pain. PLoS Med. 2016;13(5):e1002019.

13. Heymans MW, van Buuren $\mathrm{S}$, Knol DL, et al. The prognosis of chronic low back pain is determined by changes in pain and disability in the initial period. Spine J. 2010;10:847-56.

14. Vlaeyen J, Kole-Snijders A, Boeren R, et al. Fear of movement/(re) injury in chronic low back pain and its relation to behavioral performance. Pain. 1995;62(3):363-72.

15. Gheldof E, Vinck J, Vlaeyen J, et al. Development of and recovery from short- and long-term low back pain in occupational settings: a prospective cohort study. Eur J Pain. 2007;11:841-54.

16. Heneweer $\mathrm{H}$, Aufdemkampe $\mathrm{G}$, van Tulder MW, et al. Psychosocial variables in patients with (sub) acute low back pain: an inception cohort in primary care physical therapy in the Netherlands. Spine. 2007;32:586-92.

17. Swinkels-Meewisse IE, Roelofs J, Schouten EG, et al. Fear of movement/(re) injury predicting chronic disabling low back pain: a prospective inception cohort study. Spine. 2006;31:658-64.

18. Dawson AP, Schluter PJ, Hodges PW, Stewart S, Turner C. Fear of movement, passive coping, manual handling, and severe or radiating pain increase the likelihood of sick leave due to low back pain. Pain. $2011 \mathrm{Jul}$; 152(7):1517-24.

19. Lakke S, Soer R, Takken T, et al. Risk and prognostic factors for non-specific musculoskeletal pain: a synthesis of evidence from systematic reviews classified into ICF dimensions. Pain. 2009:147:153-64.

20. Staal JB, Hlobil H, Twisk JW, et al. Graded activity for low back pain in occupational health care: a randomized, controlled trial. Ann Intern Med. 2004;140(2):77-84.

21. Heymans MW, de Vet HC, Bongers PM, et al. The effectiveness of highintensity versus low-intensityback schools in an occupational setting: a pragmatic randomized controlled trial. Spine. 2006;31(10):1075-82.

22. von Elm E, Altman DG, Egger M, et al. Strengthening the Reporting of Observational Studies in Epidemiology (STROBE): Explanation and Elaboration. Ann Intern Med. 2007;147(8):573-7.

23. Carlsson AM. Assessment of chronic pain. I. Aspects of the reliability and validity of the visual analogue scale. Pain. 1983;16(1):87-101.

24. Dunn KM, Croft PR. Repeat assessment improves the prediction of prognosis in patients with low back pain in primary care. Pain. 2006; 126:10-5.

25. Brouwer S, Kuijer W, Dijkstra PU, et al. Reliability and stability of the Roland Morris disability questionnaire: intraclass correlation and limits of agreement. Disabil Rehabil. 2004;26:162-5.

26. Ostelo RW, Deyo RA, Stratford P, et al. Interpreting change scores for pain and functional status in low back pain: towards international consensus regarding minimal important change. Spine. 2008:33:90-4.

27. Ostelo RWG, de Vet HCW. Clinically important outcomes in low back pain Best Pract Res Clin Rheumatol. 2005;19:593-607.

28. Swinkels-Meewisse EJ, Swinkels RA, Verbeek AL, et al. Psychometric properties of the Tampa scale for kinesiophobia and the fear-avoidance beliefs questionnaire in acute low back pain. Manual Ther. 2003:8:29-36.

29. Buuren S, Van OK. flexible multivariate imputation by MICE. Leiden: TNO Quality of Life; 1999.

30. Fitzgerald M, Saville BR, Lewis RJ. Decision curve analysis. JAMA. 2015;313(4): 409-10.

31. Dunn KM, Campbell $P$, Jordan KP. Long-term trajectories of back pain: cohort study with 7-year follow up. BMJ Open. 2013;3(12):e003838. https://doi.org/10.1136/bmjopen-2013-003838.

32. Carey TS, Garrett JM, Jackman AM. Beyond the good prognosis. Examination of an inception cohort of patients with chronic low back pain. Spine. 2000;25:115-20.

33. Wahlgren DR, Atkinson JH, Epping-Jordan JE, et al. One-year follow-up of first onset low back pain. Pain. 1997;73:213-21.

34. Dunn KM, Jordan K, Croft PR. Characterizing the course of low back pain: a latent class analysis. Am J Epidemiol. 2006;163(8):754-61. 
35. Vickers AJ, Cronin AM, Elkin EB, et al. Extensions to decision curve analysis, a novel method for evaluating diagnostic tests, prediction models and molecular markers. BMC. 2008;8(53):1-17.

36. von Korff M, Ormel J, Keefe FJ, et al. Grading the severity of chronic pain. Pain. 1992;50(2):133-49.

37. Fritz JM, Wainner RS. Examining diagnostic tests: an evidence-based perspective. Phys Ther. 2001;81(9):1546-64.

38. Shewchuk RM, Francis KT. Principles of clinical decision making--an introduction to decision analysis. A special communication. Phys Ther. 1988; 68(3):357-9.

\section{Publisher's Note}

Springer Nature remains neutral with regard to jurisdictional claims in published maps and institutional affiliations.

Ready to submit your research? Choose BMC and benefit from:

- fast, convenient online submission

- thorough peer review by experienced researchers in your field

- rapid publication on acceptance

- support for research data, including large and complex data types

- gold Open Access which fosters wider collaboration and increased citations

- maximum visibility for your research: over $100 \mathrm{M}$ website views per year

At $B M C$, research is always in progress.

Learn more biomedcentral.com/submissions 